\title{
Cuidado, cidadania e consubstancialidade: questionando as definições de tempo, trabalho e valor
}

\author{
Gênero e trabalho no Brasil e na \\ França: perspectivas \\ interseccionais
}

ABREU, Alice Rangel Paiva; HIRATA, Helena; LOMBARDI, Maria Rosa (Orgs.).

Tradução de Carol de Paula. São Paulo: Boitempo, 2016. 284 p.

A coletânea de artigos Gênero e trabalho no Brasil e na França é resultado do Seminário Internacional Trabalho, cuidado e políticas sociais: Brasil-França em debate, realizado em São Paulo e Rio de Janeiro em agosto de 2014. A edição traz interessante nota de impressão que, além do número de cópias, cita que foi publicada 65 anos após a aprovação, pela Organização Internacional do Trabalho (OIT), da Convenção sobre a Igualdade de Remuneração de homens e mulheres trabalhadores/as por trabalho de igual valor. Os debates em nossos dias, por sua vez, inclusive na OIT, estão questionando o próprio conceito de valor.

A temática clássica do trabalho, que não deixou de ser abordada desde a emergência dos feminismos de nossa era no Brasil, tem, apesar disso, sido sub-representada nas publicações do campo em comparação a assuntos - alguns deles também clássicos - que vem recebendo destaque no debate público: a diversidade, as identidades, as migrações, as violências. Diversidade sexual e direitos reprodutivos não são diretamente abordados pelos capítulos deste livro. Contudo, as identidades, as migrações e a violência estão certamente presentes nas perspectivas interseccionais, as quais analisam o trabalho de prostitutas brasileiras no exterior, de empregadas e cuidadoras em domicílio ou em instituições, de trabalhadoras superespecializadas como engenheiras e musicistas, assim como o trabalho gratuito realizado fora da esfera produtiva - do qual esta depende diretamente. O conceito mais amplo de trabalho doméstico é foco de grande parte da obra.

O livro conta com consagrados nomes de pesquisadoras e teóricas feministas da temática trabalho, que já possuem publicações de ampla circulação no Brasil. Dentre outros, citam-se Bila Sorj, Danièle Kergoat, Helena Hirata, Jules Falquet, Laís Abramo, Maria Betânia Ávila, Maria Rosa Lombardi, Miriam Nobre, Nadya Araújo Guimarães e Tatau Godinho. As/os trinta e quatro autoras/es, envolvidas/os entre os vinte e três textos organizados em seis partes, oferecem uma profusão de pontos de vista sobre o trabalho das mulheres através das diferentes observações que são apresentadas, ainda que uma coerência teórica e também temática esteja presente no decorrer da obra.

Com mais de $60 \%$ da autoria da área da sociologia, seguida pela economia que representa pouco mais de $14 \%$, o título também conta com a participação de antropólogas e demógrafas. Estas são as áreas, com exceção da psicologia, que têm escrito de modo regular sobre trabalho desde os anos 1960 e 70 . Dentro de uma perspectiva feminista materialista bem característica da França, estas pesquisas 
pertencem à tradição teórica que cunhou termos como divisão sexual do trabalho e trabalho reprodutivo (Helena HIRATA, 2009) dentro da perspectiva de sistema sexo-gênero (HIRATA, 1989). Uma mescla de estudos de caso, análise de dados demográficos e textos teóricos compõe a coletânea.

Para o/a leitor/a iniciado/a na temática, a publicação oferece, de modo compacto, uma atualização sobre a discussão do trabalho gratuito e remunerado das mulheres com foco na realidade latino-americana - especialmente brasileira - e francesa. Por outro lado, o livro também é um meio de apresentação desses debates para o/a leitor/a mais leigo/a, que busca se familiarizar com a questão. E, sem dúvida, uma contribuição relevante ao mercado editoria brasileiro, que em muitos aspectos carece de publicações teóricas voltadas ao trabalho das mulheres, em especial à questão do trabalho não remunerado.

A obra em seus diferentes recortes parece de alguma forma, abordar, mesmo que pontualmente, as questões mais tratadas pela teoria feminista do Ocidente acerca do trabalho desde a década de 1960: a relação trabalho doméstico e emprego doméstico; a naturalização do trabalho das mulheres; o rompimento do contrato sexual (Carole PATEMAN, 1993); a permanência de desigualdades no mercado de trabalho; a invisibilidade; a permanência de determinadas atividades desvalorizadas como culturalmente femininas; o uso do tempo; a questão das estatísticas; o volume de trabalho gratuito que as mulheres prestam à sociedade; e, também, o debate do trabalho de cuidado e do afeto no trabalho. São recorrentes os momentos em que se mencionam estes focos de análise como imbricados em relações de poder. $O$ gênero, sob uma perspectiva bastante materialista, é fio condutor da coletânea ao lado da temática trabalho.

Do mesmo modo, o subtítulo "perspectivas interseccionais" antecipa para o/a leitor/a a questão de que a interseccionalidade ou consubstancialidade de categorias de análise - principalmente classe, raça e gênero - se caracteriza como o outro fio condutor ou problema aglutinador dos capítulos. No primeiro deles, O cuidado e as imbricações das relações sociais, Danièle Kergoat apresenta de forma sucinta um histórico das categorias utilizadas pelo feminismo materialista para pensar o trabalho das mulheres. Além disso, aponta as razões de sua preferência pelo uso do conceito de consubstancialidade, desenvolvido por ela no final da década de 1970, em substituição à noção de interseccionalidade ou teoria da articulação das opressões. Ela parte do conceito marxiano de relação social para constatar a necessidade de não apenas convocar as diferentes relações sociais - de sexo e classe, por exemplo - mas de colocá-las em relação umas com as outras. Essa imbricação das categorias seria a consubstancialidade. Do seu ponto de vista, a interseccionalidade seria insuficiente para suas análises, porque remeteria ao cruzamento de categorias enquanto ela, como socióloga, pretende observar as relações sociais que fabricam tais categorias.

De fato, não são todos os textos apresentados no livro que utilizam o conceito de consubstancialidade, mas eles são a maioria. Por outro lado, ocorreu a escolha política, talvez da editora, de utilizar as "perspectivas interseccionais" no título em português, que não existe na versão francesa da publicação Genre, race, classe: travailler en France et au Brésil (L'Harmattan, 2016). Esses fatores nos oferecem um vislumbre das tensões presentes no debate teórico neste campo de estudos.

Desde a presença dos sentimentos e da confiança como componentes indispensáveis no trabalho, até as medições de bem-estar coletivo e utilidade social, passando pelas conceituações de tempo que moldam as pesquisas de uso do tempo, a publicação traz profundas críticas aos modos como nossas sociedades têm desqualificado estruturalmente atividades que são essenciais para "fazer a sociedade". O tempo "feminino", o tempo da disponibilidade permanente, da sincronização cotidiana com o tempo dos outros, da antecipação, da continuidade da atenção a longo prazo, enfim, o tempo do cuidado, é apontado como aquele que deveria ser usado na concepção de políticas sociais, e não o usualmente utilizado tempo cronológico, associado às relações masculinas com o tempo. Do mesmo modo, a noção de "pobreza de tempo" recebe espaço nestes debates, nos convidando a recuperar as taxas de atividade como um produto histórico.

As questões que regem os estudos sobre cuidado, que levam em conta que todas as pessoas necessitam de cuidado - e não apenas aquelas vistas como dependentes -, assim como sua atribuição social às mulheres, ajudam a pensar o trabalho de cuidado gratuito e remunerado. Nesse âmbito se discutem as licenças parentais, a dupla jornada e o cuidado coletivo partindo das constatações da "crise do cuidado" anunciada pela OIT. A defesa de que os direitos 
devem ser universalizados, não sendo acessíveis apenas para quem tem emprego formal, é acompanhada pela percepção da permanência do "teto de vidro", o limite não institucionalizado - mas estatisticamente evidente - de acesso das mulheres aos topos das carreiras. $O$ contexto neoliberal de globalização é marcado na análise das trabalhadoras domésticas migrantes - internas, no caso do Brasil -, que lutam em nosso país em defesa da aplicação da legislação recente que as concede os direitos que as demais categorias já tinham há setenta anos.

A visão não apenas machista, mas de esquerda, de que o cuidado não seria políico, é problematizada ao lado da constatação de que a lógica de crescimento pelo crescimento precisa ser questionada. Nessas dimensões, nas quais as dinâmicas de discriminação se reatualizam, propõe-se uma renovação dos modelos econômicos e sociais. Por exemplo, o PIB, posto como fruto de uma longa história que definiu o que é produtivo e o que é riqueza, como uma história de poder, uma história industrial e uma história masculina, é questionado na obra como método eficaz de medição se for levado em conta a utilidade social das atividades. Buscando laços reais entre economia e democracia, os textos convidam-nos a, artesanalmente, repensar nossos modelos de desenvolvimento, a criar novos indicadores sem esquecer de como os indicadores são políticos, e a implodir a definição de trabalho ao considerá-lo como sendo a produção do viver em sociedade.

Importante, nesse sentido, recuperar o prefácio de Tatau Godinho (2016, p. 10), para quem "o mundo do trabalho não é só um campo de conhecimento, mas também caminho fundamental para mudar as desigualdades entre homens e mulheres". Um convite à leitura desta coletânea que, além de apresentar um atualizado diagnóstico das condições de trabalho das mulheres e uma apurada observação da produção de desigualdades, aponta para caminhos de construção de novos modelos: de trabalho, de economia e de cidadania.

\section{Referências}

GODINHO, Tatau. Prefácio. In: ABREU, Alice Rangel Paiva et al. (Orgs.). Gênero e trabalho no Brasil e na França: perspectivas interseccionais. São Paulo: Boitempo, 2016. HIRATA, Helena et al. (Orgs). Dicionário crítico do feminismo. São Paulo: UNESP, 2009.

HIRATA, Helena. Pesquisas sociológicas sobre relações de gênero na França. In: Relações Sociais de Gênero x Relações Sociais de Sexo - Núcleo de Estudos da Mulher e Relações Sociais de Gênero, USP, 1989, p. 88-100.

PATEMAN, Carole. O contrato sexual. Rio de Janeiro: Paz e Terra, 1993.

[Recebida em 19/07/2016 e aceita para publicação em 31/08/2016]

Soraia Carolina de Mello Universidade Federal de Santa Catarina, Florianópolis, Santa Catarina, Brasil

Soraia Carolina de Mello (soraiaa.mello@gmail.com). Possui graduação em História pela Universidade Federal de Santa Catarina (2007), Mestrado (2010) e Doutorado (2016) em História pela mesma instituição. Tem experiência na área de História, com ênfase em História do Brasil, principalmente nos seguintes temas: trabalho doméstico, história, imprensa feminina, imprensa feminista, gênero e consumo. 